\title{
MEASURING ARCHITECTURE: QUESTIONING THE APPLICATION OF NON-LINEAR MATHEMATICS IN THE ANALYSIS OF HISTORIC BUILDINGS
}

\author{
MICHAEL OSTWALD \\ School of Architecture and Built Environment \\ University of Newcastle \\ Callaghan, NSW 2308, Australia \\ Michael.Ostwald@newcastle.edu.au

\section{CHRIS TUCKER} \\ School of Architecture and Built Environment \\ University of Newcastle \\ Callaghan, NSW 2308, Australia
}

Chris.Tucker@newcastle.edu.au

\begin{abstract}
In the late 1970s the mathematician Benoit Mandelbrot argued that natural systems frequently possess characteristic geometric or visual complexity over multiple scales of observation. This proposition suggests that systems which have evolved over time may exhibit certain local visual qualities that also possess deep structural resonance. In mathematics this observation lead to the formulation of fractal geometry and was central to the rise of the sciences of non-linearity and complexity.

During the 1990s a number of researchers developed this concept in relation to architectural design and urban planning and more recently architectural scholars have suggested that such approaches might be used in the analysis of historic buildings. At the heart of this approach, in both its theoretical and computational forms, is a set of processes initially developed by Carl Bovill for analyzing buildings. However, the assumptions implicit in Bovill's method (itself an extrapolation of an approach proposed by Mandelbrot) have never been adequately questioned. The present paper returns to the origins of Bovill's analytical method to reconsider his original investigation of key works of $20^{\text {th }}$ century architecture and the way in which Bovill frames images for analysis. The aim of this analysis is to question several assumptions present in Bovill's method about the way in which computer technology is used to understand the visual qualities of historic buildings.
\end{abstract}




\section{Introduction}

In 1975 the mathematician Benoit Mandelbrot published Les Objects Fractals: Form Hasard et Dimension. At the core of Mandelbrot's research is an attempt to understand the geometrical rules that underlie nature. In this work Euclidean geometry, the traditional tool used in science to describe natural objects, is viewed as fundamentally unable to fulfil this purpose. While historically, science considered roughness and irregularity an aberration disguising underlying ordered systems with a fixed state or finite values, Mandelbrot (1977) argues that the fragmentation of all naturally occurring phenomena cannot so easily be disregarded. For example, a coastline is not straight and no Euclidean Geometric construct can approximate the form of a coastline without serious abstraction or artificiality. As a result of this natural fragmentation, mathematicians have shown that the length of the coastline cannot be determined at all (Feder, 1988). Yet, the characteristic irregularity of a coastline may be measured by imagining that the increasingly complicated and detailed path of the coastline is actually somewhere between a one-dimensional line and a two-dimensional surface (Schroeder, 1991). The more complicated the line, the closer it becomes to being a twodimensional surface. Therefore, coastlines and many similar natural lines can be viewed as being fractions of integers, or what Mandelbrot (1982) describes as fractal geometric forms. Thus, fractal geometry describes irregular or complex lines, planes and volumes that exist between whole number integer dimensions. This implies that instead of having a dimension, or $D$, of 1,2 , or 3 , fractals might have a $D$ of $1.51,1.93$ or 2.74 .

Architects and designers adopted fractal geometry as a design tool in the 1980s but, despite some interesting results, it rarely produced an enduring architectural response (Jencks 1995; Ostwald 2001; Ostwald 2003a). In contrast, the history of applications of fractal geometry to the analysis of architectural and urban forms is still evolving and is displaying more promising results. For example, Oku (1990) and Cooper $(2003 ; 2005)$ have separately attempted to use fractal geometry to provide a quantitative measure of the visual qualities of an urban skyline. Yamagishi, Uchida and Kuga (1988) have sought geometric complexity in street vistas and Kakei and Mizuno (1990) have applied fractal geometry to the analysis of historic street plans; a project that has been extended by Rodin and Rodina (2000). At a much finer scale, Capo (2004) has provided an explanation of the complexity of the architectural orders (Doric, lonic and Corinthian columns) using fractal geometry and Eaton (1998) has interpreted the layout and decoration of some of Frank Lloyd Wright's Houses as being fractalesque. At a larger scale Cartwright (1991) offered an overview of the importance of fractal geometry in town planning and Batty and Longley (1994) and Hillier (1996) have each developed increasingly refined methods for using fractal geometry to understand the visual and growth patterns of macro-scale urban environments.

Despite these examples, one of the more commonly repeated mathematical methods for the analysis of visual character in historic architecture is Bovill's (1996) extrapolation of Mandelbrot's box-counting approach to determining fractal dimension. Bovill's original contribution to the box-counting method rests primarily in his explanation of its potential application in architecture, design and the arts. Bovill's method has been used to analyse historic and modern building forms along with streetscapes and skylines. Since his original publication, Bovill has offered an extrapolation of its use (1997) and Bechhoefer and Appleby (1997) have used the method to consider the visual qualities of vernacular architecture. Bovill's method has been repeated by a range of researchers studying historic or vernacular forms including Makhzoumi and Pungetti (1999) and Burkle-Elizondo, Sala and Valdez-Cepeda (2004). The following sections examine Bovill's method; the purpose of this analysis is not to criticise Bovill's work but to begin the process of exploring and exposing its potential limits.

\section{Founding Assumptions}

Before considering Bovill's mathematical method, the philosophical assumptions implicit in his application of non-linear mathematics to architecture are worth examining. For example, Bovill commences his work with the argument that architecture is necessarily produced through the manipulation of rhythmic forms. He expands this to propose that fractal geometry will allow a 'quantifiable measure of the mixture of order and surprise' (3) in such rhythmic forms to be determined and, moreover, that this will reveal the essence of the architectural composition. For Bovill, "[a]rchitectural composition is concerned with the progression of interesting forms from the distant view of the facade to the intimate details. ... As one approaches and enters a building, there should always be another smaller-scale, interesting detail that expresses the overall intent of the composition' (3). However, contrary to this claim, the desire to 'maintain 
interest' or produce a cascade of detail from different perspectives is not a primary formal motivation in any major architectural theory since Roman times (Kruft 1994). Indeed, the opposite is true for much Ancient Greek and Renaissance architecture. In the former case elaborate geometric strategies (including entasis in columns) were employed to artificially correct a range of changes that occur when a building is viewed from different ranges. In the latter case, Renaissance architecture was designed to be appreciated from a singular, almost Platonic, perspective viewpoint.

In the second stage of his proposition Bovill maintains that the use of fractal analysis in architecture might explain why some modern buildings have never been fully appreciated by the general public, whereas some vernacular architecture is more widely liked (6). Bovill assumes that modern architecture (by which he means the international style architecture of mid-career Le Corbusier or Mies van der Rohe) will have a lower fractal dimension and, therefore, a lower correlation with natural geometry than historic architecture. In this proposition Bovill repeats Mandelbrot's argument which has as its founding assumption the Kantian belief that nature is innately beautiful and that people are drawn to the appreciation of natural forms because of this. For Bovill, fractal images 'are pleasant because they capture the character and depth of texture that nature displays' (70). Yet, as philosophers have observed, the Kantian belief in the essential rightness, goodness or beauty of nature is not supported by strong evidence and it does not stand up to close scrutiny. Gray (1991) and Ostwald (2003b) have also reviewed Mandelbrot's assumptions and uncovered a range of political and philosophical problems in the aesthetic and cultural values embedded in his work. For example, Mandelbrot is highly critical of Modern architecture while praising Beaux-Arts or Baroque buildings. This is problematic for a range of reasons most notably because it places an undue positive emphasis on higher fractal dimensions while dismissing those that have relatively abstract or plain forms as being alienating. However, despite Mandelbrot's assertions, fractal dimension is not a determinant of good architecture, social responsibility or cultural meaning in the built environment. Fundamentally there is no correlation between fractal dimension and successful architecture. Instead, fractal geometry remains important in architectural analysis because it is one of the few quantitative methods available that provide a measure of visual complexity, or formal density. Also, like many quantitative methods, it provides a powerful comparative tool that assists in understanding visual similarities or differences between multiple buildings.

\subsection{Counting Boxes}

At the heart of Bovill's method is 'box counting'; a mathematical approach which involves applying a range of different scale grids over an elevation of an historic building and counting the number of boxes that overlay some detail of the architecture. As the grid size changes so too does the number of boxes containing some detail of the façade elevation. This is a typical mathematical operation to produce a log-log linear correlation between the number of boxes counted and the associated size of the grid. The slope or angle of the regression line produced in this way provides an estimate of the fractal dimension of the elevation or plan. Through such an analysis, Bovill concludes, it is possible to see that while all architecture is fractal at certain scales some designs are fractal over a wider range of scales. Bovill uses two examples to explain his case; Frank Lloyd Wright's Robie House and his Unity Temple. In the former case Bovill uses four grids, and three comparisons between the grids. As a result of this analysis he determines that the façade of the Robie House has a range of fractal dimensions from $D=$ 1.645 to $D=1.441$. In an interesting validation of this result, Bovill then considers a window detail from the Robie house and finds, in Wright's elaborate stained glass patterns, a slightly higher fractal dimension. Such a result would not be unexpected in one of Wright's houses of the era (Eaton 1998). For his analysis of an elevation of Wright's Unity Temple, Bovill uses three grids and two comparisons between grids. From this process Bovill determines that the façade of the Unity Temple has a fractal range of between $D=1.621$ and $D=1.482$. Again, Bovill seeks validation of his result by analysing a smaller detail in the design; a planter box. In each of his examples Bovill uses elevation images as raw data; a method that has been repeated by other researchers ever since. However, at no stage is this choice of an elevational view questioned.

The human eye reads the world in perspective and it is impossible to experience an elevation; the problems of parallax ensure that in the 'real world' no two lines are ever, perceptually at least, parallel. Why not then use perspective views for analysis? This question is even more compelling when the fact that fractal geometry is about a comparison between different scales of viewing it is taken into account. Bovill even argues that a cascade of detail is critical for leading the eye closer to the building. Yet, Bovill's method doesn't rely on recording the change 
in detail as the eye comes closer to the building, instead it assumes that the eye (or viewpoint) remains fixed while the amount of detail entering the eye increases. This is akin to placing a digital camera on a fixed tripod and then, after manipulating the lens to perfectly correct the perspective, taking a 2 mega-pixel photo. Then, from the same position and after another level of parallax correction, a 4 mega-pixel image is taken and then an 8 mega-pixel image and so on. This process differs from Bovill's stated view of the purpose of architecture. Viewed in this way, the framing of the raw image data is critical to determining the result of the analytical process. What then might be some alternatives to Bovill's framing of the raw image data?

\subsection{Alternative Framings}

The following, seemingly more realistic variations on Bovill's method, are alternative ways of framing the image that is analysed. Each variation uses a different combination of view points, perspective planes (and picture planes where the image is ultimately recorded). These variations also introduce the role of the cone of vision; something conspicuously lacking from much fractal analysis of historic architecture. In the following descriptions, for simplicity, the methods are described for orthogonal structures. Also, it is acknowledged that in order to determine the fractal dimension of an image, a comparison of two separate 'grids' is required. Although, for the purpose of considering alternatives, the variations describe these paired grids as one conceptual view or picture plane.

\subsubsection{Fixed position, one-point perspective (fig. 1)}

This variation involves a fixed viewpoint with the eye at right angles to the dominant surface of the façade, but with no correction for parallax. This variation suggests that all images are in onepoint perspective. This variation has the advantage of a consistent rule for setting up the image composition (at right angles to the façade and a certain distance from it based on the dimensions of the building being considered and determined by a standard cone of vision).

\subsubsection{Fixed position, two-point perspective (fig. 2)}

A fixed viewpoint with the eye/camera not at right angles to the dominant surface of the façade, but with no correction for parallax. This suggests that all images are in at least two-point perspective and that the gathering of data is analogous to increasing the mega-pixel value set in the camera. This has the problem that there is no clear rule for setting the viewpoint even though the image is more natural (the fixed, one-point version is relatively artificial in its framing).



Figure 1: Fixed position, one-point pers.

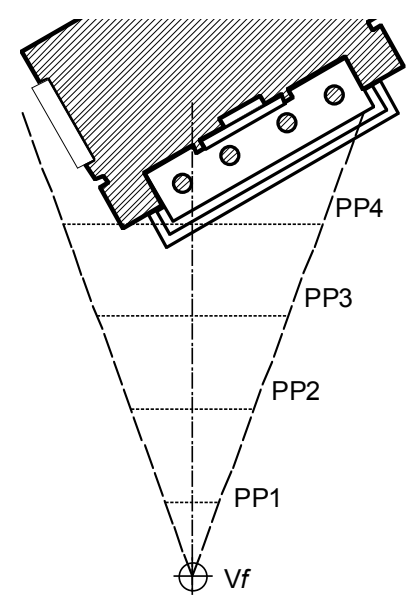

Figure 2: Fixed position, two-point pers. 


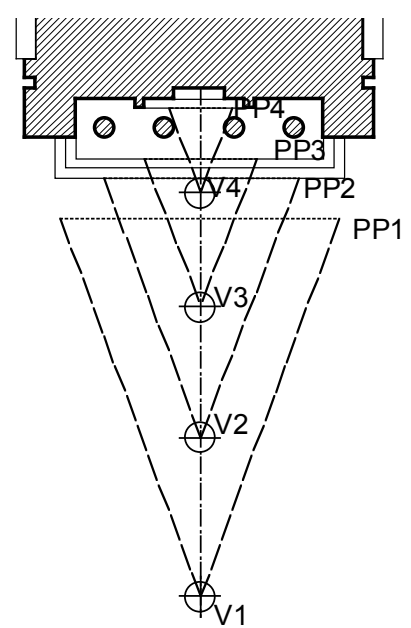

Figure 3: Variable position, one-point pers.

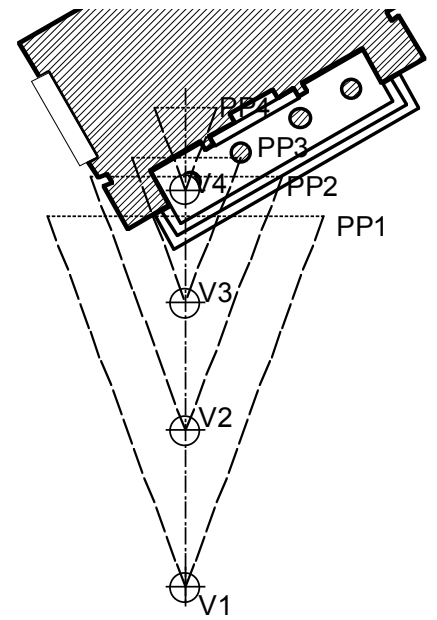

Figure 4: Variable position, two-point pers.

\subsubsection{Variable position, one-point perspective (fig. 3)}

This variation uses a range of viewpoints, starting further away from the façade and moving closer to it, but all at right angles to the dominant surface of the façade. At each viewpoint the standard cone of vision of the human eye determines the extent of the façade that is analysed. This means that, with each iteration, a reduced portion of the façade is considered.

This variation is close to the way a human eye would operate if a person walked directly towards a façade. This variation can be refined to set a range of standard viewing distances along a line to the façade allowing it to be repeatable for a wide range of circumstances.

\subsubsection{Variable position, two-point perspective (fig. 4)}

A range of viewpoints positioned along a line, starting further away from the façade and moving closer to it, are used. None of these viewpoints are at right angles to the façade's geometry but all are positioned along a single vector to the façade. At each viewpoint the standard cone of vision of the human eye determines the extent of the façade that is analysed.

\subsubsection{Variable position, multiple-point perspective (fig. 5)}

A range of viewpoints, starting further away from the façade and moving closer to it, are used. None of these viewpoints are at right angles to the façade's geometry and none are in a fixed line between the original view point and the final one (a characteristic of the other variations). At each viewpoint the standard cone of vision of the human eye determines the extent of the façade that is recorded. This is the closest of any of the methods to reality. It suggests that people rarely approach buildings along a single vector and it acknowledges the importance of the limits of human vision. However, it is hard to see how this could be easily repeated for multiple buildings (because fractal dimension in architecture is mostly useful, from an analytical point of view, as a comparative value). Notwithstanding this problem, there might be some ways to use this variation. For example, some houses can only be approached along a proscribed entry path; several of Wright's houses have hedges that line paths forcing a visitor to walk around to the rear to enter.

In such cases, where the experience of the architecture is choreographed, it would be interesting to determine the fractal dimension of the architecture (or even the landscape framed in this way) along the entry route. Such an analysis would produce a valuable numerical expression of the way a designer intends to reveal the visual qualities of a building. An alternative way of using this variation might be to compare the fractal dimension of different approaches taken by people to a building. 


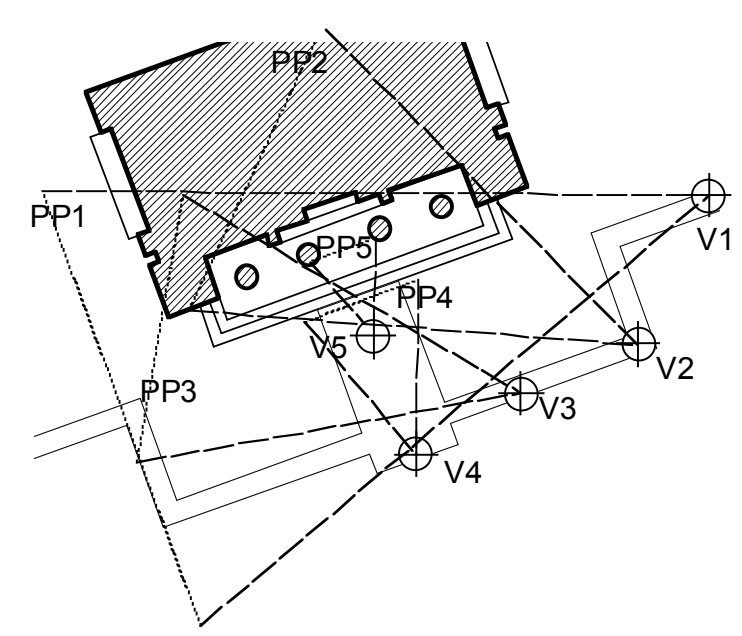

Figure Key

For figures 1 - 5;

$V f$ is a fixed viewpoint

V1-5 are sequential viewing points

PP1-5 are picture planes where an image is recorded

Figure 5: Variable position, multiple-point pers.

For example, imagine a civic building facing a piazza. A statistical analysis could be undertaken of the way in which many hundreds of people approach the building across the piazza. Imagine that, all things being equal in the piazza (ie. no physical or visual obstacles), there are three dominant paths taken by people. What would a fractal analysis of visual complexity of the environment along these three paths reveal? Would it suggest that people are drawn along similar or different visual paths? Are people drawn to the paths that maximise the visual complexity of the environment? This is certainly the untested assumption implicit in many applications of Mandelbrot's ideas in architecture.

\section{Conclusion}

This review of Bovill's method has begun to uncover a range of issues that should be refined or corrected before the method can be used as a consistent analytical tool. Ultimately, the analysis of the assumptions implicit in Bovill's method does not undermine its importance, but it does reinforce the fact that this method is not able to be used to make quality judgements about historic architecture. The method may be used to suggest the extent to which a design has multiple levels of detail, but this is not, in and of itself, any reflection of design quality, aesthetics or ethical values. Similarly, high fractal dimensions in architecture are not any more natural than low fractal dimensions; fundamentally architecture is not nature and a higher $D$ does not infer that a building is any closer to nature than a lower $D$.

In considering the way in which Bovill frames images of historic buildings for analysis a range of variations have been proposed. Each of these variations are more realistic in modelling the way in which humans experience architecture. They are superior to Bovill's method in all but one, important, way. Bovill's method, for all that it may be unrealistic, has the advantage that it is a straightforward, repeatable process. The method may not result in the most realistic or detailed results, but they are relatively consistent. Finally, the variations set out above, and especially the final one, suggest that there are powerful applications of fractal analysis that have not yet been developed or tested but which will be useful for producing a more nuanced, subtle or detailed, reading of visual complexity in the built environment.

\section{References}

Batty, Michael. Cities and Complexity: Understanding Cities with Cellular Automata, AgentBased Models, and Fractals. Cambridge Massachusetts: MIT Press, 2005.

Batty, Michael and Longley, Paul. Fractal Cities: A Geometry of Form and Function. New York: Academic Press, 1994.

Bechhoefer, William and Appleby, Marilyn. "Fractals, Music and Vernacular Architecture: An Experiment in Contextual Design." In Critical Methodologies in the Study of Traditional Environments 97 edited by AISayyad, N. Berkeley: University of California at Berkeley, Centre for Environmental Design, unpag. 1997. 
Bovill, Carl. "Fractal Calculations in Vernacular Design." In Critical Methodologies in the Study of Traditional Environments 97 edited by AlSayyad, N. Berkeley: University of California at Berkeley, Centre for Environmental Design, unpag. 1997.

Bovill, Carl. Fractal Geometry in Architecture and Design. Boston: Birkhauser, 1996.

Burkle-Elizondo, G, Sala, N, and Valdez-Cepeda, R D. "Geometric and Complex Analyses of Maya Architecture: Some Examples." In Nexus V: Architecture and Mathematics, edited by Williams, K. and Cepeda, F. D., (Florence: Kim Williams Books), 2004. 57-68.

Capo, D. "The Fractal Nature of the Architectural Orders." Nexus: Architecture and Mathematics 6(1) (2004): 30-40.

Cartwright, T J. "Planning and Chaos Theory." American Planning Association Journal 57(1) (1991): 44-56.

Cooper, J. "Fractal assessment of street-level skylines: a possible means of assessing and comparing character." Urban Morphology 7(2) (2003): 73-82.

Cooper, J. "Assessing Urban Character: The Use of Fractal Analysis of Street Edges." Urban Morphology 9(2) (2005): 95-107.

Eaton, Leonard. K. "Mathematics and Music in the Art Glass Windows of Frank Lloyd Wright." In Nexus: Architecture and Mathematics 1998. edited by Williams, K., Firenze, Italy: Edizioni Dell'Erba, 1998: 57-71.

Feder, Jens. Fractals. New York: Plenum Books, 1988.

Gray, Noel., "Critique and a Science for the Sake of Art: Fractals and the Visual Arts". Leonardo, 24(3), 1991. 317-320.

Hillier, Bill. Space is the Machine: A Configurational Theory of Architecture. Cambridge: Cambridge University Press, 1996.

Jencks, Charles. The Architecture of the Jumping Universe. London: Academy, 1995.

Kakei, $\mathrm{H}$ and Mizuno, S. "Fractal Analysis of Street Forms." Journal of Architecture, Planning and Environmental Engineering 8(414) (1990): 103-108.

Kruft, Hanno Walter. A History of Architectural Theory from Vitruvius to the Present. New York: Princeton Architectural Press, 1994.

Makhzoumi, J. and Pungetti, G. Ecological Landscape Design and Planning: The Mediterranean Context. London: E \& FN Spon, 1999.

Mandelbrot, Benoit B. Fractals: Form, Chance, and Dimension. San Francisco: W. H. Freeman and Company, 1977.

Mandelbrot, Benoit B. The Fractal Geometry of Nature. New York: W. H. Freeman and Company, 1982.

Oku, T. "On visual complexity on the urban skyline." Journal of Planning, Architecture and Environmental Engineering 8(412) (1990): 61-71.

Ostwald, Michael J. "Fractal Architecture': Late Twentieth Century Connections Between Architecture and Fractal Geometry." Nexus Network Journal, Architecture and Mathematics 3(1) (2001): 73-84.

Ostwald, Michael J. "Fractal Architecture: The Philosophical Implications of an Iterative Design Process". Communication and Cognition 36(3/4) (2003a): 263-295.

Ostwald, Michael J. "Symbols of Evolution, Signs of Regression: Mies and the Politics of Geometry." In Progress edited by Gusheh M and Stead, N. Sydney: Society of Architectural Historians, Australia and New Zealand, 2003b: 226-231.

Rodin, V and Rodina, E. "The Fractal Dimension of Tokyo's Streets." Fractals 8 (2000) : 413418.

Schroeder, Manfred. Fractals, Chaos, Power Laws: Minutes from an Infinite Paradise. New York: W. H. Freeman and Company, 1991.

Yamagishi, R, Uchida, S, and Kuga S. "An Experimental Study of Complexity and Order of Street-Vista." Journal of Architecture, Planning and Environmental Eng 2(384) (1988): 27-35. 